\title{
Prognostic value of microRNA-378 in esophageal cancer and its regulatory effect on tumor progression
}

\author{
WEI JIN ${ }^{1 *}$, LIXIN WANG ${ }^{2 *}$, SUJIE CHENG ${ }^{3}$ and HONGMEI LV ${ }^{4}$ \\ Departments of ${ }^{1}$ Gastroenterology, ${ }^{2}$ Endoscopy, ${ }^{3}$ Infectious Diseases and ${ }^{4}$ Cardiology, \\ Yidu Central Hospital of Weifang, Weifang, Shandong 262500, P.R. China
}

Received November 2, 2020; Accepted February 23, 2021

DOI: $10.3892 /$ etm.2021.10136

\begin{abstract}
The incidence and mortality rates of esophageal squamous cell carcinoma (ESCC) are high in China, which has increased the clinical and economic burden. The present study aimed to investigate the role of microRNA (miRNA/miR)-378 in ESCC. Reverse transcription-quantitative polymerase chain reaction analysis was performed to detect miR-378 expression in ESCC tissues and cell lines. Survival analysis was performed using the Kaplan-Meier method, while Cox regression analysis was performed to determine the prognostic value of miR-378 in ESCC. miR-378 mimic and miR-378 inhibitor was transfected into ESCC cells to overexpress or knockdown miR-378 expression levels in ESCC cells. The Cell Counting Kit- 8 assay was performed to assess the proliferative ability of ESCC cells, while the Transwell assay was conducted to assess the effect of miR-378 on the migratory and invasive abilities of ESCC cells. The results demonstrated that miR-378 displayed significantly lower expression both in ESCC cells and tissues by comparison with those in normal cells and adjacent tissues. In addition, patients with low miR-378 expression had a worse prognosis and a shorter overall survival time than those with high miR-378 expression. Furthermore, low miR-378 expression promoted ESCC cell proliferation, migration and invasion. Taken together, the results of the present study suggest that miR-378 may act as a tumor suppressor in the occurrence and development of ESCC.
\end{abstract}

\section{Introduction}

Esophageal carcinoma is one of the most common malignancies of the digestive system and the sixth leading cause

Correspondence to: Dr Wei Jin, Department of Gastroenterology, Yidu Central Hospital of Weifang, 4138 South Linglongshan Road, Weifang, Shandong 262500, P.R. China

E-mail: wjzen4708@163.com

${ }^{*}$ Contributed equally

Key words: microRNA-378, esophageal cancer, prognostic value, progression of cancer-associated mortality worldwide (1). Esophageal carcinoma includes esophageal squamous cell carcinoma (ESCC) and esophageal adenocarcinoma, of which ESCC is the most common pathological type in Asia $(2,3)$. Currently, the treatment strategies for ESCC include surgery, radiotherapy, and chemotherapy $(4,5)$. Despite advancements in these techniques, the 5-year survival rate of patients with ESCC was $<20 \%$ in $2012(6,7)$. Thus, it is important to identify effective biomarkers for the diagnosis and treatment of patients with ESCC $(8,9)$. In recent years, research on non-coding RNAs in the field of molecular biology has attracted great interest due to its association with tumors $(10,11)$.

MicroRNAs (miRNAs/miRs) are a class of highly conserved non-coding RNA molecules, which negatively regulate gene expression by binding to the 3 '-untranslated region of target mRNAs, resulting in mRNA degradation and inhibition of translation $(12,13)$. Increasing evidence suggest that miRNAs play key roles in gene expression regulation and signal transduction pathways in cancer $(14,15)$. It has been reported that downregulated miR-378 expression exerts a tumor suppressive role in non-small cell lung cancer (NSCLC), which provides an innovative and candidate target for the diagnosis and treatment of patients with NSCLC (16). Yang et al (17) comprehensively analyzed the role of miRNAs and mRNAs in ESCC, and microarray analysis demonstrated that miR-378 expression was abnormally downregulated in ESCC. However, the prognostic value of miR-378 and its regulatory effect on tumor progression in ESCC remain unclear.

With the aim of exploring effects of miR-378 on ESCC, the present study determined the expression levels of miR-378 in ESCC tissues and cell lines, and then analyzed the correlation between its expression and clinical parameters as well as the prognosis value for ESCC. Preliminarily, the molecular mechanism of action of miR-378 on ESCC was investigated.

\section{Materials and methods}

Patients and tissue samples. A total of 135 patients with ESCC at Yidu Central Hospital were enrolled in the present study between June 2013 and June 2015. The mean age for all patients was 62 years old with a range of 38-72 years; 
males slightly predominated (54\%). Included cases were histopathologically confirmed to have ESCC and all patients agreed to participate in the study. Patients who had previously received any radiation or chemotherapy for ESCC prior to surgery were excluded from the present study. Other eligibility criteria were as following: $\geq 18$ years of age; and no history of concurrent cancer in other organs or history of previous cancer in any organ. Pathological tissue samples and paired normal tissue samples $(5 \mathrm{~cm}$ away from the tumor tissues) were collected via surgical resection. The fresh specimens were immediately frozen in liquid nitrogen and stored at $-80^{\circ} \mathrm{C}$ until subsequent experimentation. Patients were classified according to the seventh edition of TNM staging criteria for malignant tumors, as revised by the International Union against Cancer and the American Cancer Federation in 2009 (18). The present study was approved by the Medical Ethics Committee of Yidu Central Hospital of Weifang (Weifang, China; approval no. 201210) and written informed consent was provided by all patients prior to the study start. Survival analysis was performed via a 5-year telephone follow-up study (from the date of surgery treatment to death or the last observation).

Cell culture and transfection. The ESCC cell lines TE-1, KYSE-150, Eca-109 and TE-8 were purchased from the Cell Bank of Type Culture Collection of the Chinese Academy of Sciences, while the human esophageal epithelial cell line, Het-1A, was purchased from the American Type Culture Collection. All cells were maintained in RPMI-1640 medium (Invitrogen; Thermo Fisher Scientific, Inc.) supplemented with $10 \%$ fetal bovine serum (FBS; Thermo Fisher Scientific, Inc.), at $37^{\circ} \mathrm{C}$ with $5 \% \mathrm{CO}_{2}$. miR-378 mimic $(50 \mathrm{nM}$; 5'-CUC CUGACUCCAGGUCCUGUGU-3'), mimic negative control (NC, $50 \mathrm{nM}$; 5'-UCACAACCUCCUAGAAAGAGUAGA-3'), miR-378 inhibitor (50 nM; 5'-ACACAGGACCUGGAGUCA GGAG - $3^{\prime}$ ) and inhibitor NC (50 nM; 5'-UUCUCCGAACGU GUCACGUTT-3') were synthesized by Guangzhou RiboBio Co., Ltd. $20 \mathrm{nM}$ of miR-378 mimic or inhibitor transfection mix was prepared in Lipofectamine ${ }^{\circledR} 3000$ reagent (Invitrogen; Thermo Fisher Scientific,Inc.), according to the manufacturer's instructions. The transfection mix and $1.5 \times 10^{5}$ cells were seeded in medium in the same 6 -well plates at $37^{\circ} \mathrm{C}$. Following $24 \mathrm{~h}$, the medium along with the transfection reagent was replaced with fresh medium. After another $24 \mathrm{~h}$ of medium replacement at $37^{\circ} \mathrm{C}$, the cells were harvested for the subsequent experimentation.

$R N A$ reverse transcription-quantitative polymerase chain reaction ( $R T-q P C R)$. Total RNA was extracted from ESCC tissues and cells using TRIzol ${ }^{\circledR}$ reagent (Invitrogen; Thermo Fisher Scientific, Inc.), and the RNA quality and quantity were verified using a NanoDrop 2000 (Thermo Fisher Scientific, Inc.). Total RNA was reverse transcribed into cDNA using the TaqMan miRNA reverse transcription kit (Thermo Fisher Scientific, Inc.) using the following temperature protocol: $16^{\circ} \mathrm{C}$ holding for $30 \mathrm{~min}, 42^{\circ} \mathrm{C}$ for $30 \mathrm{~min}, 85^{\circ} \mathrm{C}$ for $5 \mathrm{~min}$ and then $4^{\circ} \mathrm{C}$. qPCR was subsequently performed using the SYBR-Green I Master mix kit (Invitrogen; Thermo Fisher Scientific, Inc.) on an ABI 7500 system. The amplification of U6 small nuclear RNA was used for the normalization.
The primers used in the present study were as follows: U6 forwards, 5'-CGCTTCACGAATTTGCGTGTCAT-3' and reverse 5'-GCTTCGGCAGCACATATACTAAAAT-3'; and miR-378-5p forwards, CAAACCTCCTCCTGACTCCAG and reverse, TATGCTTGTTCTCGTCTCTGTGTC. The PCR conditions were as follows: $95^{\circ} \mathrm{C}$ for $30 \mathrm{sec}$; and 40 cycles of $95^{\circ} \mathrm{C}$ for $5 \mathrm{sec}$ and $60^{\circ} \mathrm{C}$ for $30 \mathrm{sec}$ and $72^{\circ} \mathrm{C}$ for $20 \mathrm{sec}$. Relative expression levels were calculated using the $2^{-\Delta \Delta \mathrm{Cq}}$ method (19). All experiments were performed in triplicate.

Cell proliferation assay. Of the four ESCC cell lines, miR-378 expression was significantly lower in TE-1 and KYSE-150 cells compared with Eca-109 and TE-8 cells. Thus, the TE-1 and KYSE-150 cell lines were selected for subsequent experimentation. Transfected TE-1 and KYSE-150 cells were centrifuged at $100 \mathrm{x}$ g for $5 \mathrm{~min}$ at $4{ }^{\circ} \mathrm{C}$. Thereafter, the cell suspension was prepared in RPMI-1640 medium containing 10\% FBS and then seeded into 96-well plates at a density of $2 \times 10^{3}$ cells per well. Subsequently, $10 \mu 1$ Cell Counting Kit-8 (CCK-8) reagent (Dojindo Molecular Technologies, Inc.) was added to each well and incubated for $1-2 \mathrm{~h}$ at $37^{\circ} \mathrm{C}$, with $5 \% \mathrm{CO}_{2}$. Cell proliferation was analyzed at a wavelength of $450 \mathrm{~nm}$, using a microplate reader system (Molecular Devices LLC).

Cell migration and invasion assays. TE-1 and KYSE-150 cells were starved for 24 hours in a serum-free medium before invasion or migration experiments. A total of $2 \times 10^{5}$ transfected ESCC cells were plated in the upper chambers of Transwell plates ( $8 \mu \mathrm{m}$ pores; BD Biosciences), and finally, $200 \mu 1$ serum-free RPMI-1640 was added to the upper chamber. At $37^{\circ} \mathrm{C}$, the cells were cultured for $24 \mathrm{~h}$ in an incubator with $5 \% \mathrm{CO}_{2}$. For the invasion assay, Transwell membranes were precoated with Matrigel. RPMI-1640 medium (Invitrogen; Thermo Fisher Scientific, Inc.) supplemented with $10 \%$ FBS was plated in the lower chambers. Cells were fixed with $4 \%$ paraformaldehyde solution for $20 \mathrm{~min}$ at room temperature and subsequently stained with $0.1 \%$ crystal violet for $20 \mathrm{~min}$ at room temperature. Stained cells were counted in five randomly selected fields using an Olympus IX-70 fluorescence microscope at 200x magnification.

Statistical analysis. Statistical analysis was performed using SPSS 21.0 software (IBM Corp.) and GraphPad Prism 5.0 software (GraphPad Software, Inc.). All experiments were performed in triplicate and data are presented as the mean \pm standard deviation. Paired Student's t-test was used to compare differences between two groups, while one-way ANOVA and Tukey's post-hoc tests were used to compare differences between multiple groups. $\chi^{2}$ test was used to compare the association between miR-378 expression and clinic data of patients. Survival analysis was performed using the Kaplan-Meier method and compared with the use of log-rank test to determine the statistical significance. Univariate and multivariate Cox regression analysis was performed to determine the prognostic value of miR-378 in ESCC. $\mathrm{P}<0.05$ was considered to indicate a statistically significant difference. 
Table I. Association between miR-378 expression and the clinicopathological characteristics of patients with esophageal squamous cell carcinoma $(n=135)$.

miR-378 expression

\begin{tabular}{|c|c|c|c|c|}
\hline \multirow{2}{*}{ Characteristic } & \multirow[b]{2}{*}{ Number of patients } & & \multirow[b]{2}{*}{ P-value } \\
\hline & & Low $(n=68)$ & High $(n=67)$ & \\
\hline Age, years & & & & 0.793 \\
\hline$<65$ & 64 & 33 & 31 & \\
\hline$\geq 65$ & 71 & 35 & 36 & \\
\hline Sex & & & & 0.790 \\
\hline Male & 73 & 36 & 37 & \\
\hline Female & 62 & 32 & 30 & \\
\hline Smoking & & & & 0.550 \\
\hline No & 82 & 43 & 39 & \\
\hline Yes & 53 & 25 & 28 & \\
\hline Drinking & & & & 0.673 \\
\hline No & 77 & 40 & 37 & \\
\hline Yes & 58 & 28 & 30 & \\
\hline Differentiation degree & & & & 0.788 \\
\hline Middle/High & 60 & 31 & 29 & \\
\hline Low & 75 & 37 & 38 & \\
\hline TNM stage & & & & 0.001 \\
\hline $\mathrm{I} / \mathrm{II}$ & 102 & 43 & 59 & \\
\hline III & 33 & 25 & 8 & \\
\hline Lymph node metastasis & & & & 0.010 \\
\hline Negative & 95 & 41 & 54 & \\
\hline Positive & 40 & 27 & 13 & \\
\hline
\end{tabular}

miR, microRNA; TNM, tumor-node-metastasis.
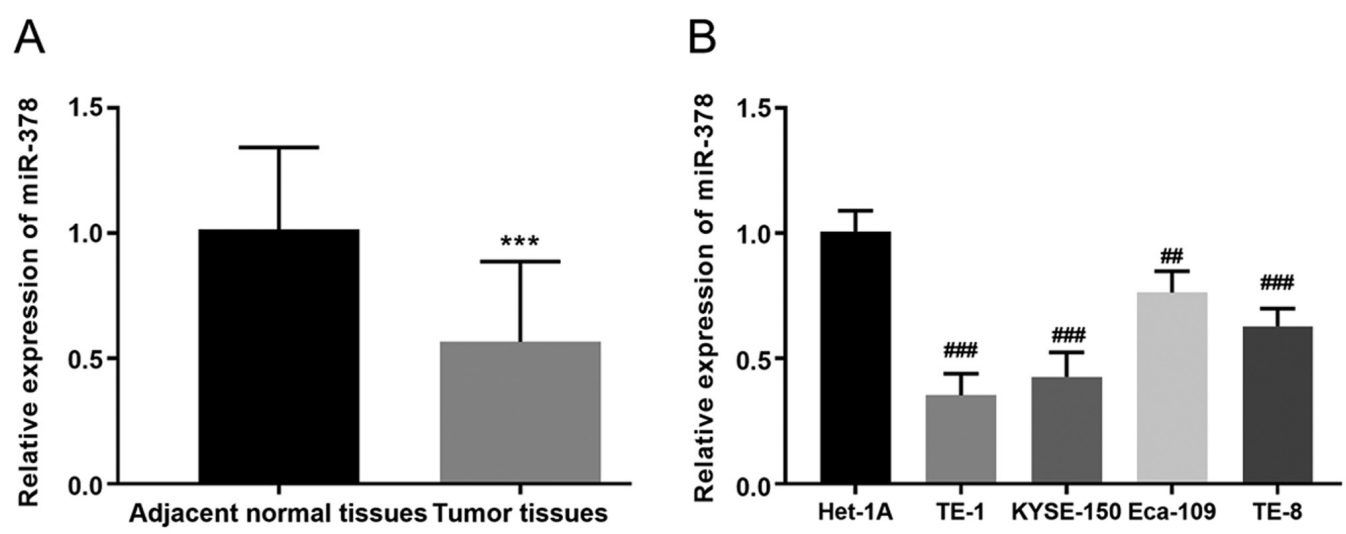

Figure 1. miR-378 expression in ESCC tissues and cell lines. (A) miR-378 expression in ESCC tissues and adjacent normal tissues. (B) miR-378 expression in the four ESCC cell lines and normal Het-1A cells. ${ }^{* * * *} \mathrm{P}<0.001$ vs. adjacent normal tissues; ${ }^{\# \#} \mathrm{P}<0.01,{ }^{\# \#} \mathrm{P}<0.001$ vs. Het-1A cells;. miR, microRNA; ESCC, esophageal squamous cell carcinoma.

\section{Results}

miR-378 expression in ESCC tissues and cell lines. RT-qPCR analysis was performed to detect miR-378 expression in ESCC tissues and cell lines. The results demonstrated that miR-378 expression was significantly lower in ESCC tissues $(0.567 \pm 0.321)$ compared with adjacent normal tissues (1.02 \pm 0.326 ; P<0.001; Fig. 1A). Similarly, miR-378 expression was significantly lower in the four ESCC cell lines compared with the normal cell line, particularly in KYSE-150 and TE-1 cells $(\mathrm{P}<0.01, \mathrm{P}<0.001$, Fig. $1 \mathrm{~B})$. Notably, miR-378 expression was three times higher in Het-1A cells compared with KYSE-150 cells, and twice as high compared with TE-1 cells. 
Table II. Multivariate Cox regression analysis for overall survival in patients with esophageal squamous cell carcinoma.

\begin{tabular}{|c|c|c|c|c|c|c|}
\hline \multirow[b]{2}{*}{ Variable } & \multicolumn{3}{|c|}{ Univariate analysis } & \multicolumn{3}{|c|}{ Multivariate analysis } \\
\hline & HR & $95 \% \mathrm{CI}$ & P-value & HR & $95 \% \mathrm{CI}$ & P-value \\
\hline MicroRNA-378 expression & 2.124 & $1.053-4.283$ & 0.035 & 2.516 & $1.088-5.817$ & 0.031 \\
\hline Age & 1.031 & $0.544-1.952$ & 0.926 & 1.546 & $0.756-3.160$ & 0.232 \\
\hline Sex & 0.892 & $0.468-1.700$ & 0.729 & 0.507 & $0.239-1.078$ & 0.078 \\
\hline Smoking & 1.089 & $0.568-2.089$ & 0.797 & 1.075 & $0.544-2.126$ & 0.835 \\
\hline Drinking & 1.373 & $0.710-2.656$ & 0.347 & 1.575 & $0.795-3.121$ & 0.193 \\
\hline Differentiation degree & 1.329 & $0.703-2.514$ & 0.382 & 1.027 & $0.501-2.107$ & 0.942 \\
\hline TNM stage & 1.612 & $0.709-3.662$ & 0.254 & 2.801 & $1.031-7.606$ & 0.043 \\
\hline Lymph node metastasis & 0.393 & $0.208-0.745$ & 0.004 & 0.426 & $0.191-0.947$ & 0.036 \\
\hline
\end{tabular}

TNM, tumor-node-metastasis; HR, hazard ratio; CI, confidence interval.

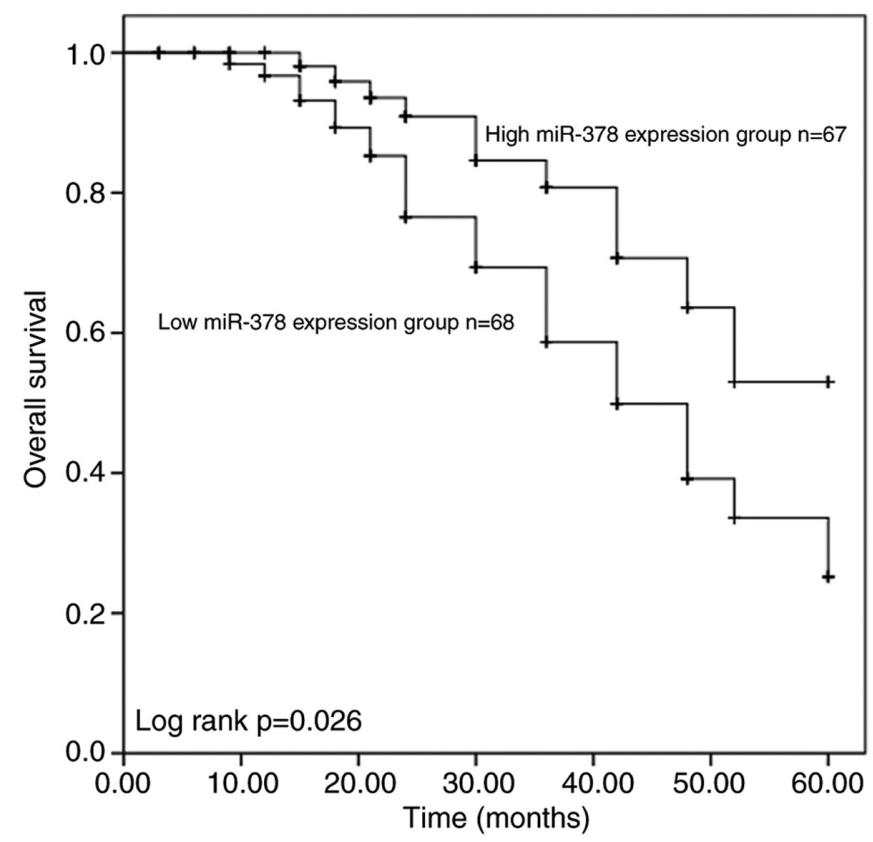

Figure 2. Kaplan-Meier survival analysis of patients with esophageal squamous cell carcinoma, based on miR-378 expression. miR, microRNA.

Association between miR-378 expression and the clinicopathological characteristics of patients with ESCC. The median relative expression of miR-378 was used as the threshold $(20,21)$. All patients were divided into two groups, the miR-378 high expression group $(\mathrm{n}=67)$ and the miR-378 low expression group $(\mathrm{n}=68)$. The results demonstrated that miR-378 expression was significantly associated with the TNM stage $(\mathrm{P}=0.001)$ and lymph node metastasis $(\mathrm{P}=0.01)$ of patients with ESCC. However, no significant associations were observed between miR-378 expression and age, sex, smoking, drinking or tumor differentiation degree among patients with ESCC (P>0.05, Table I).

miR-378 expression is associated with survival outcomes of patients with ESCC. Survival analysis was performed using the Kaplan-Meier method and log-rank test, based on miR-378 expression. The results demonstrated that patients with low miR-378 expression had a significantly shorter overall survival time $(\mathrm{P}=0.026$; Fig. 2$)$ than those with high miR-378 expression. Furthermore, univariate and multivariate Cox regression analysis indicated that miR-378 expression [ $\mathrm{P}=0.031$; hazard ratio (HR), 2.516], TNM staging $(\mathrm{P}=0.043$; HR, 2.801) and lymph node metastasis $(\mathrm{P}=0.036$; $\mathrm{HR}, 0.426)$ are independent prognostic factors for overall survival in patients with ESCC (Table II).

Downregulation of miR-378 expression promotes cell proliferation, migration and invasion. Following transfection with miR-378 mimics, mimic NC, miR-378 inhibitors and inhibitor NC, miR-378 expression in TE-1 and KYSE-150 cells was detected via RT-qPCR analysis. The results demonstrated that transfection with miR-378 mimic significantly increased miR-378 expression, the effects of which were reversed following transfection with miR-378 inhibitor $(\mathrm{P}<0.01$, Fig. $3 \mathrm{~A})$. The CCK- 8 assay was performed to assess cell proliferation. The results demonstrated that overexpression of miR-378 inhibited the proliferation of ESCC cells, while miR-378 knockdown promoted the proliferation of ESCC cells compared with the control groups $(\mathrm{P}<0.05$, Fig. 3B).

The results of the Transwell assay demonstrated that the number of migratory and invasive cells significantly decreased in TE-1 and KYSE-150 cells following transfection with miR-378 mimic, the effects of which were reversed following transfection with miR-378 inhibitor $(\mathrm{P}<0.01$; Fig. 4A and B).

\section{Discussion}

miRNAs can regulate the expression of target genes at the post-transcriptional level (22-24). It has been confirmed that approximately one third of genes in the human genome are regulated by miRNAs (25). Several studies have demonstrated that miRNAs play important roles in the occurrence and development of tumors, functioning as either oncogenes or tumor suppressors in different types of cancer $(13,26,27)$. ESCC is a common malignancy worldwide, which is a major 

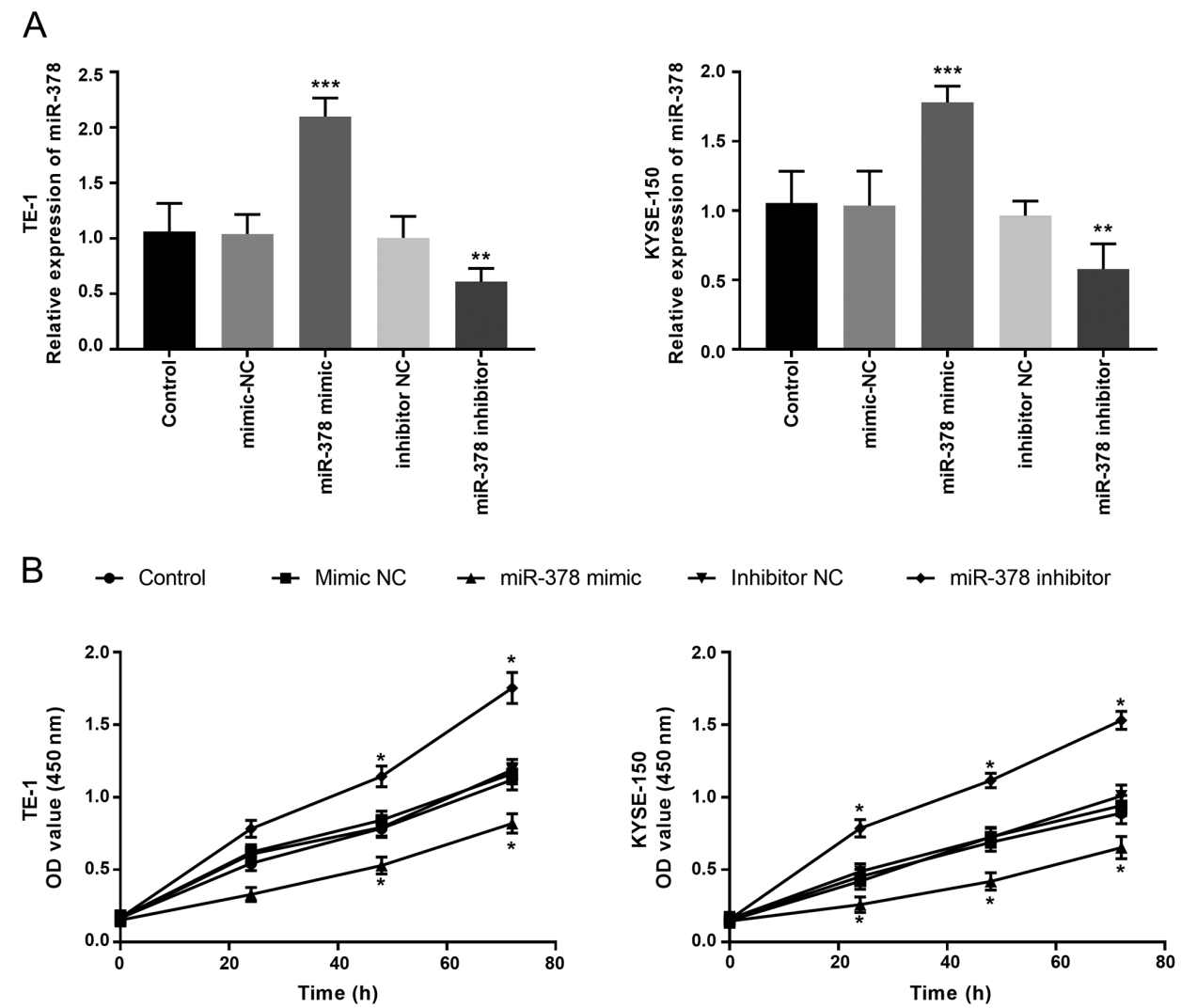

Figure 3. Effect of miR-378 on the proliferative ability of TE-1 and KYSE-150 cells. (A) Reverse transcription-quantitative polymerase chain reaction analysis was performed to detect miR-378 expression in TE-1 and KYSE-150 cells following transfection with miR-378 mimic and inhibitor (or mimic/inhibitor NC), (B) The Cell Counting Kit-8 assay was performed to assess cell proliferation. ${ }^{*} \mathrm{P}<0.05,{ }^{* * *} \mathrm{P}<0.01,{ }^{* * * *} \mathrm{P}<0.001$ vs. the control group. miR, microRNA; NC, negative control; OD, optical density.
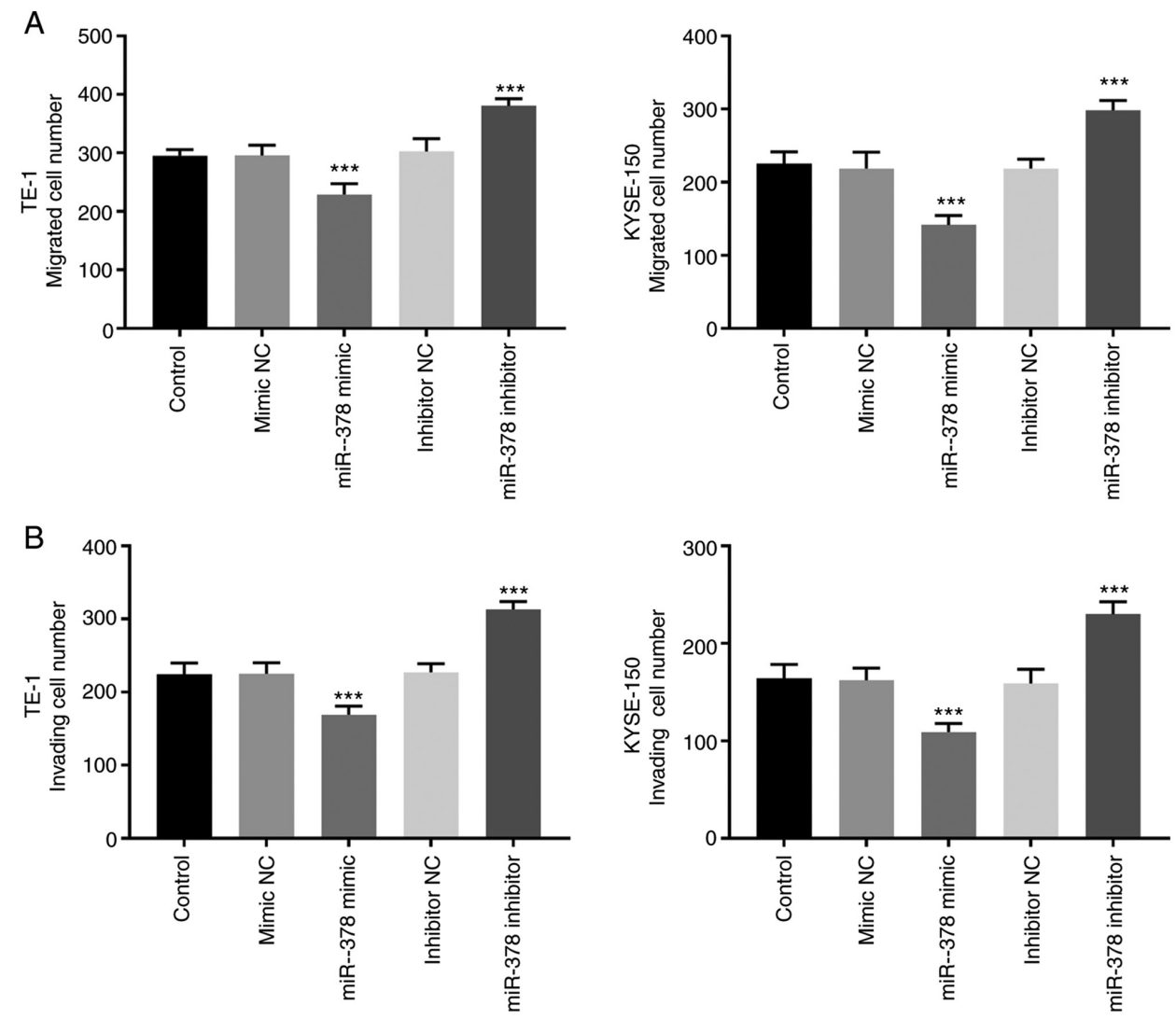

Figure 4. Effect of miR-378 on the migratory and invasive abilities of TE-1 and KYSE-150 cells. (A) Cell migratory and (B) invasive abilities were assessed using Transwell assays. ${ }^{* * *} \mathrm{P}<0.001$ vs. the control group. miR, microRNA; NC, negative control. 
threat to human health $(5,28)$. Given that the molecular mechanisms underlying the occurrence and progression of esophageal carcinoma are not yet fully understood, the prognosis of patients remains poor $(4,29,30)$. Thus, it is important to identify effective molecular targets and novel therapeutic strategies for patients with esophageal carcinoma $(31,32)$.

Previous studies have reported that miR-378 plays an important role in different types of cancer. For example, Li et al (33) demonstrated that miR-378 expression is significantly lower in glioma tissues compared with non-neoplastic brain tissues, and downregulated miR-378 expression is associated with tumor invasiveness and poor prognosis of patients with glioma. In colorectal cancer, miR-378 expression is significantly downregulated in colorectal cancer tissues and cell lines, and low miR-378 expression predicts a shorter overall survival acting as an independent prognostic factor (34).

The results of the present study demonstrated an association between miR-378 expression and the progression of ESCC. The results indicated that miR-378 expression was significantly downregulated in ESCC tissues compared with normal adjacent tissues, suggesting that miR-378 may inhibit ESCC progression. In tumors, TNM stage represents the degree of tumor development, and lymph node metastasis is an important factor affecting the survival of patients. In the present study, patients with low miR-378 expression exhibited an advanced TNM stage and positive lymph node metastasis. In addition, Kaplan-Meier survival analysis and multivariate Cox regression analysis demonstrated that patients with low miR-378 expression had a poor prognosis. Taken together, these results suggest that miR-378 may serve as a potential prognostic marker for ESCC.

Zeng et al (35) reported that miR-378 expression is downregulated in colon cancer tissues and cell lines, and that overexpression of miR-378 inhibits the proliferation, migration and invasion of colon cancer cells. Furtherly, cell proliferative, migratory and invasive abilities are usually associated with the development of tumors (36). Thus, the present study assessed the effect of altering miR-378 expression on the biological behaviors of ESCC cells via cell transfection. The results demonstrated that miR-378 knockdown promoted the proliferation, migration and invasion of ESCC cells, while overexpression of miR-378 inhibited these cellular behaviors compared with untreated ESCC cells. Collectively, these results suggest that miR-378 plays an inhibitory role in ESCC.

miR-378 has been reported to exert similar inhibitory effects in other types of cancer, for instance, low ectopic miR-378 expression inhibits the proliferation, migration and invasion of MGC-803 gastric cancer cells, suggesting that miR-378 exerts an anticancer role in gastric cancer (37). This may provide novel diagnostic and therapeutic options for the future clinical management of human gastric cancer (37). Taken together, the results of the present study are consistent with previous findings $(35,38,39)$.

The present study is not without limitations, such as, the sample size used was too small or the downstream target genes of miR-378 have not yet been fully investigated. Thus, further studies are required to confirm the results presented here.

In conclusion, the results of the present study demonstrated that miR-378 expression was downregulated in ESCC tissues and cell lines, which was associated with a poor prognosis of patients with ESCC. Notably, miR-378 may act as a tumor suppressor in the occurrence and development of ESCC.

\section{Acknowledgements}

Not applicable.

\section{Funding}

No funding was received.

\section{Availability of data and materials}

The datasets used and/or analyzed during the current study are available from the corresponding author on reasonable request.

\section{Authors' contributions}

WJ, LW and HL conceived and designed the present study. All authors performed the experiments. WJ, LW and SC analyzed and interpreted the data. WJ and LW drafted the initial manuscript. HL critically revised the manuscript for important intellectual content. All authors have read and approved the final manuscript. WJ, LW and HL confirm the authenticity of all the raw data.

\section{Ethics approval and consent to participate}

The present study was approved by the Medical Ethics Committee of Yidu Central Hospital of Weifang (Weifang, China, approval no. 201210) and written informed consent was provided by all patients prior to the study start.

\section{Patient consent for publication}

Not applicable.

\section{Competing interests}

The authors declare that they have no competing interests.

\section{References}

1. Alsina M, Moehler M and Lorenzen S: Immunotherapy of esophageal cancer: Current status, many trials and innovative strategies. Oncol Res Treat 41: 266-271, 2018.

2. Dong Z, Wang J, Zhan T and Xu S: Identification of prognostic risk factors for esophageal adenocarcinoma using bioinformatics analysis. Onco Targets Ther 11: 4327-4337, 2018.

3. Hou J, Zou K, Yang C, Leng X and Xu Y: Clinicopathological and prognostic significance of circulating tumor cells in patients with esophageal cancer: A meta-analysis. Onco Targets Ther 11: 8053-8061, 2018.

4. Hirano H and Kato K: Systemic treatment of advanced esophageal squamous cell carcinoma: Chemotherapy, molecular-targeting therapy and immunotherapy. Jpn J Clin Oncol 49: 412-420, 2019.

5. Reichenbach ZW, Murray MG, Saxena R, Farkas D, Karassik EG, Klochkova A, Patel K, Tice C, Hall TM, Gang J, et al: Clinical and translational advances in esophageal squamous cell carcinoma. Adv Cancer Res 144: 95-135, 2019.

6. Dong Z, Wang J,Zhang H,Zhan T, Chen Y and Xu S: Identification of potential key genes in esophageal adenocarcinoma using bioinformatics. Exp Ther Med 18: 3291-3298, 2019.

7. Siegel R, Naishadham D and Jemal A: Cancer statistics, 2012. CA Cancer J Clin 62: 10-29, 2012. 
8. Jamali L, Tofigh R, Tutunchi S, Panahi G, Borhani F, Akhavan S, Nourmohammadi P, Ghaderian SMH, Rasouli M and Mirzaei H: Circulating microRNAs as diagnostic and therapeutic biomarkers in gastric and esophageal cancers. J Cell Physiol 233: 8538-8550, 2018.

9. Li Y,Huang HC, Chen LQ, Xu LY, Li EM and Zhang JJ: Predictive biomarkers for response of esophageal cancer to chemo(radio) therapy: A systematic review and meta-analysis. Surg Oncol 26 : 460-472, 2017.

10. Jiang Z, Song Q, Yang S, Zeng R, Li X, Jiang C, Ding W, Zhang J and Zheng Y: Serum microRNA-218 is a potential biomarker for esophageal cancer. Cancer Biomark 15: 381-389, 2015.

11. Mei LL, Qiu YT,Zhang B and Shi ZZ: MicroRNAs in esophageal squamous cell carcinoma: Potential biomarkers and therapeutic targets. Cancer Biomark 19: 1-9, 2017.

12. Correia de Sousa M, Gjorgjieva M, Dolicka D, Sobolewski C and Foti M: Deciphering miRNAs' action through miRNA editing. Int J Mol Sci 20: 20, 2019.

13. Mishra S, Yadav T and Rani V: Exploring miRNA based approaches in cancer diagnostics and therapeutics. Crit Rev Oncol Hematol 98: 12-23, 2016.

14. Kang M, Li Y, Zhu S, Zhang S, Guo S and Li P: MicroRNA-193b acts as a tumor suppressor gene in human esophageal squamous cell carcinoma via target regulation of KRAS. Oncol Lett 17: 3965-3973, 2019.

15. Xia D, Tian S, Chen Z, Qin W and Liu Q: miR-302a inhibits the proliferation of esophageal cancer cells through the MAPK and PI3K/Akt signaling pathways. Oncol Lett 15: 3937-3943, 2018.

16. Ji KX, Cui F, Qu D, Sun RY, Sun P, Chen FY, Wang SL and Sun HS: miR-378 promotes the cell proliferation of non-small cell lung cancer by inhibiting FOXG1. Eur Rev Med Pharmacol Sci 22: 1011-1019, 2018

17. Yang H, Su H, Hu N, Wang C, Wang L, Giffen C, Goldstein AM, Lee MP and Taylor PR: Integrated analysis of genome-wide miRNAs and targeted gene expression in esophageal squamous cell carcinoma (ESCC) and relation to prognosis. BMC Cancer 20: 388, 2020.

18. Edge S, Byrd DR, Compton CC, Fritz AG, Greene F and Trotti A (eds): AJCC Cancer Staging Manual. 7th Edition. Springer-Verlag, New York, NY, 2010.

19. Livak KJ and Schmittgen TD: Analysis of relative gene expression data using real-time quantitative PCR and the 2(-Delta Delta C(T)) Method. Methods 25: 402-408, 2001

20. Goto T, Fujiya M, Konishi H, Sasajima J, Fujibayashi S, Hayashi A, Utsumi T, Sato H, Iwama T, Ijiri M, et al: An elevated expression of serum exosomal microRNA-191, - 21, -451a of pancreatic neoplasm is considered to be efficient diagnostic marker. BMC Cancer 18: 116, 2018.

21. Nie X, Su Z, Yan R, Yan A, Qiu S and Zhou Y: MicroRNA-562 negatively regulated c-MET/AKT pathway in the growth of glioblastoma cells. Onco Targets Ther 12: 41-49, 2018.

22. Lu TX and Rothenberg ME: MicroRNA. J Allergy Clin Immunol 141: 1202-1207, 2018.

23. Rupaimoole R and Slack FJ: MicroRNA therapeutics: Towards a new era for the management of cancer and other diseases. Nat Rev Drug Discov 16: 203-222, 2017.
24. Tomaselli S, Panera N, Gallo A and Alisi A: Circulating miRNA profiling to identify biomarkers of dysmetabolism. Biomarkers Med 6: 729-742, 2012.

25. Zhang C, Ji Q, Yang Y, Li Q and Wang Z: Exosome: Function and role in cancer metastasis and drug resistance. Technol Cancer Res Treat 17: 1533033818763450, 2018.

26. Lee YS and Dutta A: MicroRNAs in cancer. Annu Rev Pathol 4: 199-227, 2009.

27. Vishnoi A and Rani S: MiRNA biogenesis and regulation of diseases: An overview. Methods Mol Biol 1509: 1-10, 2017.

28. Codipilly DC, Qin Y, Dawsey SM, Kisiel J, Topazian M, Ahlquist D and Iyer PG: Screening for esophageal squamous cell carcinoma: Recent advances. Gastrointest Endosc 88: 413-426, 2018.

29. Fu JH: Biomarkers of predicting response to neoadjuvant chemoradiotherapy in esophageal cancer. Zhonghua Wei Chang Wai Ke Za Zhi 16: 805-810, 2013 (In Chinese).

30. Hou X, Wen J, Ren Z and Zhang G: Non-coding RNAs: New biomarkers and therapeutic targets for esophageal cancer. Oncotarget 8: 43571-43578, 2017.

31. Su X, Gao C, Feng X and Jiang M: miR-613 suppresses migration and invasion in esophageal squamous cell carcinoma via the targeting of G6PD. Exp Ther Med 19: 3081-3089, 2020.

32. Yi Y, Lu X, Chen J, Jiao C, Zhong J, Song Z, Yu X and Lin B: Downregulated miR-486-5p acts as a tumor suppressor in esophageal squamous cell carcinoma. Exp Ther Med 12: 3411-3416, 2016.

33. Li B, Wang Y, Li S, He H, Sun F, Wang C, Lu Y, Wang X and Tao B: Decreased expression of miR-378 correlates with tumor invasiveness and poor prognosis of patients with glioma. Int $\mathrm{J}$ Clin Exp Pathol 8: 7016-7021, 2015.

34. Zhang GJ, Zhou H, Xiao HX, Li Y and Zhou T: miR-378 is an independent prognostic factor and inhibits cell growth and invasion in colorectal cancer. BMC Cancer 14: 109, 2014.

35. Zeng M, Zhu L, Li L and Kang C: miR-378 suppresses the proliferation, migration and invasion of colon cancer cells by inhibiting SDAD1. Cell Mol Biol Lett 22: 12, 2017.

36. Nie X, Xia F, Liu Y, Zhou Y, Ye W, Hean P, Meng J, Liu H, Liu L, Wen J, et al: Downregulation of Wnt3 suppresses colorectal cancer development through inhibiting cell proliferation and migration. Front Pharmacol 10: 1110, 2019.

37. Fei B and Wu H: MiR-378 inhibits progression of human gastric cancer MGC-803 cells by targeting MAPK1 in vitro. Oncol Res 20: 557-564, 2012

38. Guo XB, Zhang XC, Chen P, Ma LM and Shen ZQ: miR-378a-3p inhibits cellular proliferation and migration in glioblastoma multiforme by targeting tetraspanin 17. Oncol Rep 42: 1957-1971, 2019.

39. Cui Z, Sun S, Liu Q, Zhou X, Gao S, Peng P and Li Q: MicroRNA-378-3p/5p suppresses the migration and invasiveness of oral squamous carcinoma cells by inhibiting KLK4 expression. Biochem Cell Biol 98: 154-163, 2020. 